\title{
ALCANCES DE UN MÉTODO DE ANÁLISIS DE LA BALANZA AGROALIMENTARIA DE MÉXICO
}

\author{
SCOPE OF A METHOD OF ANALYSIS OF THE AGRI-FOOD BALANCE OF MEXICO
}

\author{
Germán Martínez-Prats ${ }^{1} *$ (D) \\ 1. Universidad Juárez Autónoma de Tabasco \\ División Académico de Ciencias Económico Administrativas, México \\ *Correspondencia del Autor: Germán Martínez-Prats, correo electrónico: germanmtzprats@hotmail.com
}

\section{RESUMEN}

La información del intercambio comercial de mercancías agroalimentarias que se realiza en México se compila a través del Instituto Nacional de Estadística y Geografía (INEGI) el cual registra la Estadística de Comercio Exterior de México (ECEM), cuya información permite toma de decisiones en materia comercial y financiera. Sin embargo, no se ha desarrollado un método que permita validar los datos de volumen importado y exportado de las operaciones comerciales mediante un agente aduanal, por lo que existe un sobre registro de los datos. Por ello, la propuesta de establecer un método de validación de las importaciones y exportaciones agroalimentarias considerando los volúmenes por fracción arancelaria y unidad de medida, así como los incoterms, para generar un registro específico permitirá obtener información más confiable, la cual resultará de interés para la toma decisiones de los actores involucrados en el comercio exterior.

Palabras clave: Comercio exterior; exportación; importación; mercancía; mecanismo de validación; pedimento aduanal.

Cómo citar:

Martínez-Prats, Germán. (2020). Alcances de un método de análisis de la balanza agroalimentaria de México. Revista de Investigaciones Universidad del Quindio, 32(1), 66-70. https://doi.org/10.33975/ riuq.vol32n 1.436 


\begin{abstract}
The information on the commercial exchange of agri-food goods that takes place in Mexico is compiled through the National Institute of Statistics and Geography (INEGI) which registers the Foreign Trade Statistics of Mexico (ECEM), whose information allows decision-making in commercial matters and financial. However, a method has not been developed to validate the imported and exported volume data of commercial operations through a customs agent, so there is an over-registration of the data. Therefore, the proposal to establish a validation method for agri-food imports and exports considering the volumes by tariff fraction and unit of measure, as well as the incoterms, to generate a specific record will allow obtaining more reliable information, which will be of interest to the decision-making of the actors involved in foreign trade.
\end{abstract}

Keywords: Foreign trade; export; import; merchandise; validation mechanism; customs clearance.

\section{INTRODUCCIÓN}

La balanza comercial agroalimentaria es el registro del intercambio entre importaciones $y$ exportaciones de mercancías agropecuarias y agroindustriales, exclusivamente (Secretaría de Agricultura y Desarrollo Rural, 2019).

Las fuentes primarias de información de la Balanza agroalimentaria de México, son los registros de entrada y/o salida de las operaciones comerciales que se llevan a cabo en cada una de las aduanas. Para su control, el Servicio de Administración Tributaria (SAT) ha implementado el Sistema de Automatización Aduanera Integral (SAAI M3), que consiste en un proceso de validación (Dirección de Metodología y Producción Estadística, 2007) de pedimentos aduaneros que da lugar a un intercambio de información entre agentes y apoderados aduanales, por una parte, y la autoridad aduanera por la otra. Con base en lo anterior, el SAT integra mensualmente un disco compacto que contiene los datos preliminares relativos a las operaciones de la Balanza agroalimentaria.

Esta información es de gran utilidad debido a que permite analizar la evolución y estructura de la balanza agroalimentaria (Cardero \& Mendoza, 2006), así como para evaluar la interacción que se registra entre la actividad comercial y el com- portamiento de la economía nacional.

El problema subyacente es que no existe en este momento un método que nos permita conocer el volumen en unidades de esas operaciones, ya que el actual método solo indica el valor monetario de las mismas. Por lo anterior, el desarrollo una metodología permite homologar la información y de esta manera contar con datos confiables para la toma de decisiones en los distintos sectores de la economía, y lograr la estandarización de los importes de transacciones comerciales internacionales con los volúmenes de dichas operaciones.

\section{METODOLOGÍA}

El artículo "Alcances de un método de análisis de la balanza agroalimentaria de México" señala la importancia de un método de análisis para validar y/o ajustar los datos de la balanza agroalimentaria de México en una serie de información (INEGI, 2017), que permita estandarizar los volúmenes de las mercancías importadas y exportadas, a partir del cual se genere información de mayor calidad que exprese adecuadamente las operaciones comerciales de exportación e importación de productos agroalimentarios.

Para el señalamiento y análisis de una metodología se partió de una búsqueda de información 
estadística, documental que conciliara en un proceso de propuesta metodológica para el pertinente método de análisis. Se define como un tipo de investigación mixto derivado de que participa de la naturaleza de la investigación documental y de la investigación de campo (Sampieri, 2003). En ese mismo sentido, la investigación documental se realiza a través del análisis de la información contenida en la balanza de los años o periodos requeridos.

Para ello, se considera desarrollar un método de análisis para validar y/o ajustar los datos de la balanza agroalimentaria de México en una serie de información en periodos de tres, cinco o diez años, dependiendo del interés del periodo de análisis; la cual permitirá estandarizar los volúmenes de las mercancías importadas y exportadas, a partir del cual se genere información de mayor calidad que exprese adecuadamente la realidad de las operaciones comerciales de exportación e importación de productos agroalimentarios.

El sustento de la recopilación de la información es con base a las fuentes primarias de información de la balanza agroalimentaria de México, los registros de entrada y/o salida de las operaciones comerciales que se llevan a cabo en cada una de las aduanas. Para su control, el programa del SAT identificado como SAAI M3, ejecuta un proceso de validación de pedimentos aduaneros que da lugar a un intercambio de información entre agentes y apoderados aduanales, por una parte, y la autoridad aduanera por la otra.

Se considera la información del SAT de forma mensual tangible en un disco compacto el cual integra los datos preliminares relativos a las operaciones de la balanza agroalimentaria. Es precisamente que esta información servirá para analizar la evolución y estructura de la balanza agroalimentaria, así como para evaluar la interacción que se registra entre la actividad comercial y el comportamiento de la economía nacional. Con la información antes descrita se busca plantea la importancia de una metodología que permita homologar la información y de esta manera contar con datos confiables para la toma de decisiones en los distintos sectores de la economía, y lograr la estandarización de los importes de transacciones comerciales internacionales con los volúmenes de dichas operaciones.

\section{RESULTADOS}

El método descrito es un aliciente en poder identificar las áreas de oportunidad, para el desarrollo económico nacional, con base a los resultados obtenidos en el análisis de los volúmenes de las operaciones de comercio exterior, permitiendo también conocer el impacto de las exportaciones agroalimentarias en la economía nacional (Moreno, 1998), de esta manera poder generar programas de apoyo a sectores específicos de la industria nacional (Carrillo, 2004).

La estadística está basada en la TIGIE del año a seleccionar debe incluir las exportaciones e importaciones de mercancías para cierto número de secciones, cierto número de capítulos, cantidad establecida de partidas, número de sub partidas y número de fracciones arancelarias aproximados. Es importante, destacar que, tanto en la exportación como en la importación, el INEGI (2015) incorpora la Sección XXIII con la finalidad de incluir el capítulo 99 y la fracción 99.99.99.99 (Códigos arancelarios no catalogados en la tarifa), todas aquellas operaciones de comercio exterior (2010) que desde su origen presentan inconsistencias de captura o registro, y por lo tanto no se pueden clasificar en códigos específicos de la TIGIE. Además de los incoterms (Mexico International Chamber of Commerce, 2010), para generar un registro específico permitirá obtener información más confiable

Asimismo, se presentan códigos arancelarios a 6 dígitos que se emplean para describir operaciones especiales y se podrán identificar con la descripción siguiente: «Operaciones especiales reportadas en códigos a 6 dígitos», facilitando a los usuarios la agregación o acumulación de cifras correspondientes al valor de las mercancías a nivel de 2, 4, 6 y 8 dígitos. 
Cabe destacar que la ECEM utiliza el Sistema Comercial General; además siguiendo las recomendaciones internacionales en la materia, las importaciones se asignan al país de origen y las exportaciones al último país de destino conocido, tomando como base lo declarado a través del pedimento aduanal correspondiente; las operaciones de tipo triangular no se identifican y los bienes de procesamiento se valoran en términos brutos.

Las exportaciones se valoran FOB (Free on Board), que en español es equivalente a LAB (libre a Bordo) y se refiere al valor de venta de las mercancías en la aduana de salida. Asimismo, las importaciones se valoran $\mathrm{FOB}$, de acuerdo con el valor comercial de compra de las mercancías en el lugar de procedencia, por lo que el importe de fletes, seguros y demás gastos incurridos para hacer llegar la mercancía a la aduana de entrada, se consignan en un renglón por separado. Lo anterior, explica que la suma de las importaciones FOB, más los gastos de fletes y seguros dan como resultado las importaciones CIF (Cost, Insurance and Freight), que en español es equivalente a CSF (Costos, Seguros y Fletes).

Finalmente, este método pretende ser un método de estandarización de los volúmenes de las importaciones y exportaciones que permita analizar datos en una serie de tiempo.

\section{DISCUSIÓN}

El mantenimiento de la calidad de la información utilizada se considera un elemento vital para otorgar confianza en información generada, por lo cual se desarrolla un Sistema Integral del Aseguramiento de la Calidad de los procesos de generación, integración y difusión de la información estadística y geográfica, en el cual se aplican las mejores prácticas internacionales en la materia, dichas prácticas son generadas y aplicadas por Organismos Internacionales, los cuales han desarrollado procesos, normas, lineamientos, sistemas, procedimientos e instrumentos que han probado su eficacia para el aseguramiento de la calidad en la generación, integración y difusión de la información estadística y geográfica.

Lo señalado en el párrafo anterior describe que ha representado avances importantes, pero aun no se alcanza la estandarización de los volúmenes de las mercancías que conforman la Balanza Comercial (INEGI, 2018), pues el sistema no considera como un insumo primordial la fracción arancelaria, y al tratarse de un mismo producto, se puede llegar a clasificar en distintas fracciones, pero una misma fracción representa siempre el mismo producto, tampoco toma en cuenta el régimen aduanero, si es temporal, definitivo, en tránsito, generándose así discrepancias en la información obtenida, son estos elementos que permitirá la estandarización de los volúmenes.

El método descrito permite conocer las áreas de oportunidad en materia agroalimentaria para los empresarios del sector, así como también establecer mecanismos de apoyo a sectores en los que se es autosuficiente y de esta forma generar seguridad alimentaria.

\section{REFERENCIAS}

1. Cardero, E., Mántey, G., \& Mendoza, M. Á. (2006). What is wrong with economic liberalization? The Mexican Case. Investigación Económica, LXV, 19-43.

2. Carrillo, J. (2004). Principales estadísticas de la industria maquiladora. Encuesta sobre aprendizaje tecnológico y escalamiento industrial. Tijuana, B.C.: Colegio de la Frontera Norte. https:// searchworks.stanford.edu/view/5681493

3. Dirección de Metodología y Producción Estadística. (2007). Guía para la Estandarización de la Validación de la Información de Comercio Exterior. Quito, Ecuador.

4. Instituto Nacional de Estadística y Geografía. (2015). Balanza comercial de Mercancías de México. Recuperado de www.inegi.org.mx 
5. Instituto Nacional de Estadística y Geografía. (2017). Balanza Comercial de Mercancías de México. Síntesis metodológica 2017. México. www.inegi.org.mx

6. Instituto Nacional de Estadística y Geografía. (2018). Balanza comercial. http://www.beta.inegi. org.mx/temas/balanza/

7. Mexico International Chamber of Commerce. (2010). Las nuevas reglas Incoterms 2010. https:// www.iccmex.mx/comisiones-de-trabajo/incoterms-2010/las-reglas-incoterms

8. Moreno-Brid, J. C. (1998). México: crecimiento económico y restricción de la balanza de pagos. Revista Comercio Exterior, 347(5). http://revistas.bancomext.gob.mx/rce/magazines/347/5/ RCE5.pdf

9. Sampieri, R. (2003). Metodología de la investigación. México: McGraw-Hill.

10. Secretaría de Agricultura y Desarrollo Rural. (2019). Balanza agroalimentaria un reporte de crecimiento constante. https://www.gob.mx/agricultura/es/articulos/balanza-agroalimentaria-unreporte-de-crecimiento-constante?idiom=es

11. Secretaría de Economía. (2010). Complejidad del Comercio Exterior. México. 